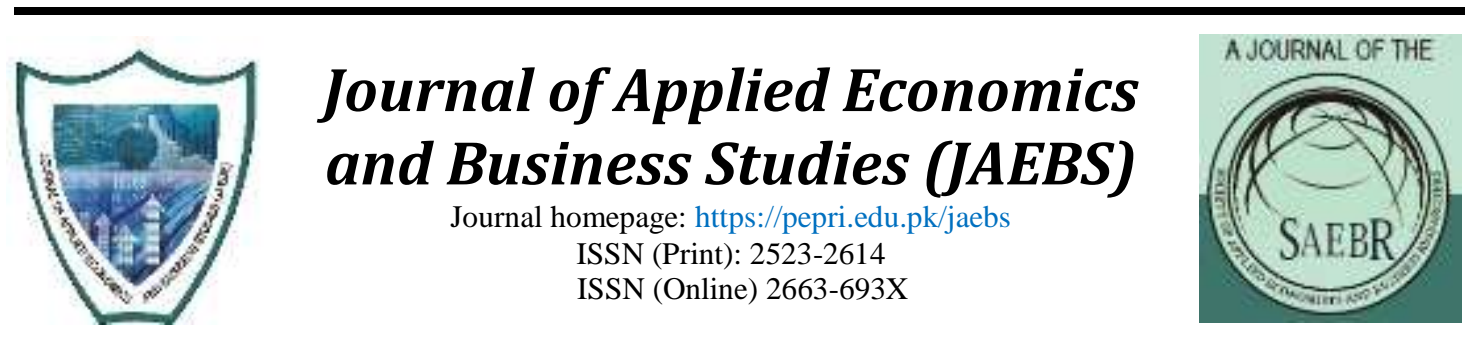

\title{
Contribution of Spatial Concentration in Exaggerating Inequalities: Across Various Urban Regions of Pakistan
}

Uzma Tabassum $^{1 *}$, Shaista Alam ${ }^{2}$ and Ambreen Fatima ${ }^{3}$

${ }^{1} \mathrm{PhD}$ Scholar and Research Assistant, Applied Economics Research Centre (AERC), University of Karachi

${ }^{2}$ Senior Research Economist, Applied Economics Research Centre (AERC), University of Karachi

${ }^{3}$ Senior Research Economist, Applied Economics Research Centre (AERC), University of Karachi

\begin{abstract}
Industrial agglomeration and inequalities are much of the concerns in recent literature. Pakistan, being a developing country, is also restricted by resource availability to treat all regions equally with respect to investment and development. As a result, regions with growing agglomeration experience higher income levels relative to other regions. To investigate this empirically this study employed propensity score matching (PSM) across urban regions in Pakistan using Labour Force Survey data 2017-18. For agglomeration regional herfindahl indices were estimated and regions with above average index value along with having positive index growth were considered as treated or agglomerated regions. The positive and significant coefficient of regions with treatment signifies that regions with agglomeration were found to have higher relatively income. Hence introducing industrial concentration in untreated regions would be effective in reducing inequalities rather tackling them by reducing agglomeration in agglomerated regions.
\end{abstract}

Keywords

Inequality, Agglomeration, Propensity

Score

Matching, Urban Regions, Herfindahl Index.

JEL

Classification

C31; D30; D3; O14; O15;

\section{Introduction}

Over the last few epochs world trends draw attention to two apparent traits in economic growth. One is rising inequalities and the other is increasing geographical concentration of economic activities across regions. Various strands of the theory suggest that openness of region and removal of barriers in free mobility of factor will probably result in a higher level of concentration of industries and as a result greater specialization of the region. This might have repercussions in growing income disparities across regions. Such growth is also observable in Pakistan where unbalanced

*uzma_tbsm@hotmail.com

The work is the part of $\mathrm{PhD}$ thesis under process. 
growth strategy is pervaded because of resource constraints (Tabassum, 2016). Therefore investments and economic activities concentrate in some regions of the country that amplifies inequalities across regions, as the exogenous characteristics of regions, skill composition of the workforce and agglomeration economies attributed to productivity differences that in turn assumed to be reflected in income distribution. Given that the distributions of industries are not uniform across regions in an effort to specifically elicit the effect of agglomeration on spatial disparities it is important to know that how the concentration of industries affect the growth process of a particular region. What is the role of urbanization and localization economies in provoking spatial disparities? How these spatial disparities are connected with inequalities in the income distribution of individuals living in that region?

The various regions would be different in sizes with respect to their physical and economic structure, depending on the agglomeration behaviour. The swiftness and assortment of industrial agglomeration in a region describe the economic conditions of that region. On the theoretical side, the concept of Agglomeration economies define the process of clustering of firms in close proximity to one another to exploit the benefits of being together within intension to minimize per-unit cost of production or achieved economies of scale (UN-HABITAT, 2011). The concept was first acknowledged by Weber (1909) while the detailed explanation of the sources of these economies was given by Marshall (1890). Marshall (1890) provided three bases through which economies of scale can be achieved. According to him agglomeration enables firms to economize on their unit cost by sharing knowledge regarding efficient production technologies and management strategies. Further Firms may agglomerate to share supply of intermediate inputs. The demand for intermediate input is greater when there are many firms located at the same place the average cost of providing such intermediate inputs to each firm will be low as high demand enable the producer of intermediate input to achieve scale economies. Lastly Sharing labour pool benefit firm when the variation in firm product demand is greater than the variation in industry level demand. The labour Fired from the firm that is facing low product demand can be hired by a firm that is facing high product demand. For doing so firm have to bear no cost for searching and training labour thus declining unit cost for two reasons: one by firing unwanted labours by a firm facing low product demand. And secondly by reducing search and training cost by high product demand firm. Duranton \& Puga (2004) also describe all these as a process of learning, sharing and matching.

In a nutshell productivity and income growth of region positively affect by agglomeration but these positive effects may come from urbanization economies or localization economies. In localization economies firms that belong to a single industry cluster together to exploit agglomeration benefits thus they specialize in that particular industry production. While in urbanization economies firms that belong to different industries cluster together to exploit agglomeration benefits that results diversified 
production. In viewpoint of efficiency spatial inequalities may have positive and negative effects. Inequalities resulting from regional specialization based on localization economies may be beneficial as it increases productivity but if these are caused by external economies or urbanization economies then they may not be optimal (Kim, 2008). Spatial inequalities caused by unrestrained population concentration in large primate cities may inflict many social ills in society. Thus spatial inequalities possibly are undesirable for society if it provoke social inequalities across the region.

This research seeks to shed some light on the process of agglomeration and its effect on the income of region that experiencing these agglomerations. The literature focusing spatial disparities between urban regions based on agglomeration are rather scarce in the context of Pakistan. A recent set of empirical literature both nationally and internationally majorly investigated the determinants of income inequalities. These studies point out socio-economic, political and open economy variables to contribute in influencing inequalities. Disaggregating these determinants includes individual and region specific variables such as education, health, gender etc. for the former and industrial clustering, policies and public service provision, agglomeration patterns etc. for the later (Sial et al, 2018., Fambon, 2017., Naseer \& Ahmed, 2016., Burki \& Khan, 2012., Davtyan; 2014., Jamal, 2006). Extensive research is already available domestically on the aspects explaining prevalence of regional inequalities but it largely focuses on socio-economic determinants of inequalities while the impact of location specific industrial clustering on embellishing inequalities has mainly overlooked. This research will evaluate the contribution of spatial concentration in inflating inequalities across various regions by exploring the likelihood of prosperous region become more prosperous, as heterogeneity across industrial expansion and in labour demand frames inequalities among individuals.

The empirical assessment is based on survey data conducted by the Pakistan Bureau of Statistics (PBS). In the study large cities and other urban areas have taken as spatial units. Because some urban regions were not included in past years survey so they left intentionally from recent sets of survey to avoid inconsistency in data overtime. For estimating the agglomeration impact, this study used the Labour Force Survey (LFS) for the period of 2017-18. Further to identify the urban regions that are experiencing persistent inter-temporal spatial concentration in the case of Pakistan, the Herfindahl indices are computed for the years 2010 and 2018. The regions that have above average level of agglomeration in a most recent period and positive growth from the base year marked as treated regions. The study used non-parametric Propensity Score Matching (PSM) techniques to overcome the problem of selection bias arise due to the selection of regions who received treatment-spatial agglomeration, particularly in nonexperimental designs. This research is a value addition to existing literature of Pakistan as it is the first study that employed propensity score matching to study agglomeration linkages with spatial inequalities arises from the unbalanced growth of regions. Further, it also contributes in empirical literature by estimating Herfindahl index for spatial 
concentration at regional level over time which is used as a base for identification of treated and untreated urban regions.

The rest of the paper is proceed by highlighting empirical literature done nationally and internationally, followed by the review of theoretical model, section four sheds light on the estimation technique and data employed, section five discusses the results and final section wrap up finding and expected policy implications.

\section{Review of Literature}

Spatial concentration of industries is placed among the highest feature of economic activity in both developed and seeking to be developed nations. A vast existing empirical literature suggest that industries are unevenly distributed across spatial units because of difference in transportation cost, immediacy to market, presence of skilled and cheap worked force and natural locational advantage etc. Thus industries agglomerate in a few regions more than others that are comparatively less attractive (Ellison \& Glaser; 1997, Maurel \& Sedilot, 1999 and Abid \& Mushtaq, 2011). Geographic concentration and regional specialization of industries were seen by many researchers as to be two sides of the same coin. Specialization of region and concentration of industries in specific location were defined using the analogous production structures as base so as to reflect the same reality which is evident from various studies in the existing literature of regional economics (Aiginger, 1999).

It was since $19^{\text {th }}$ and $20^{\text {th }}$ century that researchers were modeling regional specialization and geographical concentration rooting from trade theory and location theory respectively and conducting empirical studies on them. The literature about regional concentration probably commence with Krugman (1991). Krugman (1991) was the one which estimated Gini coefficient to capture concentration in various regions by comparing the regional market shares for a single industry with manufacturing's employment structure. Setting a traditionally localized industry (automotive industry) as a benchmark he found that large numbers of industries were localized though most of these were not cutting-edge and that industries related to high technology sectors such as textile, were highly clustered. However estimated concentration of such industries was not solely depends on technological spillover and what he found was biased in terms of the data he got. Aiginger \& Rossi-Hansberg (2006) deliberated regional specialization and geographical concentration as the two sides of the coin and theses two could be calculated from the same matrix showing industries in rows and geographical regions in columns. For the estimation of specialization columns are to be measured while for that of concentration rows are to be considered. Aiginger \& Davies (2004) using a mathematical model pointed out that if inequalities across columns vary so does it varies across rows.

The pragmatic evidence on the relationship between agglomeration economies and regional inequalities in developed nations may have immense importance. Geppert et al 
Journal of Applied Economics and Business Studies, Volume. 4, Issue 4 (2020) 187-214 https://doi.org/10.34260/jaebs.449

(2008) explored this connection in the context of West Germany using data from 1980 to 2000 and suggest that industrial agglomeration can be a considerable contributor to regional income differentiation. They find that the number of regions that are already rich with large agglomeration of industries has succeeded in further distancing themselves from the others. Thus, concentration of industries has sizeable contribution to spatial income differentiation. Larger agglomerated regions such as Munich, Hamburg and Frankfurt are leading among the richer regions that are becoming richer and showing a sign of urbanization economies. Though, the analysis does not ascertain the particular nature of causal mechanism that could be underlying this relationship.

Kim (2008) surveyed the theoretical and empirical literature about spatial and regional inequalities. The survey of literature underscores that endowment of resources, proximity to port and increasing returns attributable to concentration of human interaction increases spatial inequalities. All these are beneficial for region to enhance their productivity therefore these regions grow relatively with faster rate of growth. However congestion cost and excessive urban concentration may be harmful. Thus, in equilibrium there is an optimal level of spatial disparities to combat with inefficient level of agglomeration. Midelfart (2004) examined the role played by agglomeration of economic activities, as measured by density of employment, and composition of labour force skills in explaining regional income difference in the Norwegian economy especially focusing on Norway's manufacturing sector. Using data for the sub-regional NUTS 4 spatial units of Norway for two time period $1989 \& 1999$ the study concluded that high income seems to be an upshot of agglomerated economic activities in contrast to differences in skill composition of labor force. Two different measures of income are considered as a proxy to measure Income disparities, per hour GDP of employees and mean hourly earnings. Considering GDP per hour the regional inequalities are found significant and much more distinct relative to earnings per hour. Further disparities shows widening trend while considering GDP per hour in contrast to the result of average hourly earnings which shows reduction in regional disparities for same time span.

Regional specialization and the geographic concentration patterns of manufacturing industries as measured by dissimilarity index in Bulgaria, Estonia, Hungary, Romania and Slovenia had changed during 1990-1999 (Traistaru et al., 2002). They found that in Bulgaria and Romania regional specialization had increased with no significant changes in Estonia, Hungary and Slovenia. Further they found that large economies of scale, high technology and high wages were associated with highly concentrated industries therefore agglomeration of these industries foster the growth of these region in which they clustered. On the other hand industries with low technology and low wages were more likely to be dispersed spatially.

Glaeser et al (1992) and Henderson et al (1995) have made decisive contributions to the empirical literature focus on urban area-city. They estimate the effect of city 
employment growth on specialization and diversification index. The specialization index is measured as a proportion of industry employment to the total employment of city. The diversity index computed by Glaeser et al (1992) is calculate by taking the employment share of five largest industries in the city while Henderson et al (1995) measured diversity index as employment share of all industry in the city aggregate employment. Glaeser et al (1992) also include the inverse of plant average size as a competition index. The result of Gleaeser's model shows that city growth is positively associated with diversity index and negatively by specialization and competition index. Along with specialization and diversification index Henderson et al (1995) also used city employment in all other industries as an additional urbanization variable and found positive impact of both specialization and overall employment on the growth of employment. Focusing on the role of agglomeration of industries in specific regions as pedestal of productivity effects and developmental impulses Fan \& Scott (2003) investigates the interconnections between economic growth and geography in the developing countries of East Asia. Findings indicate that agglomeration and productivity have strong association in Chinese industries, especially electronics, computer and garments industries since the public policies in china follows economic liberalization.

The scrutiny of empirical literature done in Pakistan indicates that, the literature on agglomeration is usually focuses on the extent with which industries agglomerate in a particular region and the effect of agglomeration on the efficiency of similar and dissimilar firms in a local system. Burki \& Khan (2011) measure agglomeration of industries using data taken from Census of Manufacturing Industries (CMI). As per results the agglomeration is pervasive in Pakistani industries, the $35.3 \%$ industries are profoundly agglomerated. While, $38.2 \%$ industries are somewhat less agglomerated and $26.5 \%$ Pakistani industries are dispersed. District population, increase in road density, skilled worked force are found significant contributor in promoting spatial concentration of industries. Chaudhry \& Haroon (2015) evaluate the economic impact of new firm in the market using Punjab's Directory of Industries for the year 2002, 2006 and 2010. The finding indicates that new firm entry has noteworthy effect on socioeconomic outcome. Some of these outcomes are immediate while some outcomes become visible with lag. They recommended that policy makers should be familiar with nature of firm as impacts of new firm differ with the type of firms that affirms the need of specific industrial policy.

Azhar \& Adil (2019) explore the effect of agglomeration on social inclusion \& firm efficiency for Punjab districts. Social inclusion is made of mortality rate, antenatal care, improved water \& sanitation which then compressed into a single variable using factor component analysis. The results demonstrate that agglomeration is positively associated with firm efficiency and also it has significant association with social-inclusion. The districts with higher agglomeration also experience higher social inclusion. In developed nations the empirical evidence on spatial inequalities and agglomeration may 192 
contain immense importance, the pattern of agglomeration and its impact on spatial inequalities in developing nations like Pakistan is crucial to study. But despite the obvious policy concerns, there has been no empirical work found that explores the role of agglomeration in defining the income level of that region where these agglomerations take place. This study tries to fill the gap that is evident in the literature.

\section{The Review of Selected Theoretical Model}

In the theoretical literature the most cited work is the "New Economic Geography (NEG)" model put forward by Krugman (1991). Researchers have based their empirical findings on the theoretical arguments placed by New Economic Geography (NEG) model. According to NEG model spatial inequality is the net effect of two contrasting forces, one is centripetal force and the other is centrifugal force. Centripetal forces determine agglomeration or concentration of economic activities that is caused by imperfect competition, increasing returns to scale and mobility of factor. On the other side centrifugal forces such as congestion, high transportation cost, restricted mobility of factor encourages dispersion of economic activities. When the cost of supplying goods at far off places would is high then firm would be dispersed around markets that are immobile. In contrast when transportation cost is low immobile market can easily get access to distinct places that encourage firms to agglomerate at particular place gaining advantages of economies of scale and externalities. The region that experiencing increasing agglomeration also come up with higher economic activities which results in spatial inequalities showing the positive inter relation (Curve AA). At certain level higher agglomeration will results in increase congestion and negative externalities offsetting the positive gain of agglomeration. Consequently a new relationship established between agglomeration and spatial inequality that is opposite to the previous one (Curve RR).

Figure-1: Nexus between income growth and regional inequalities

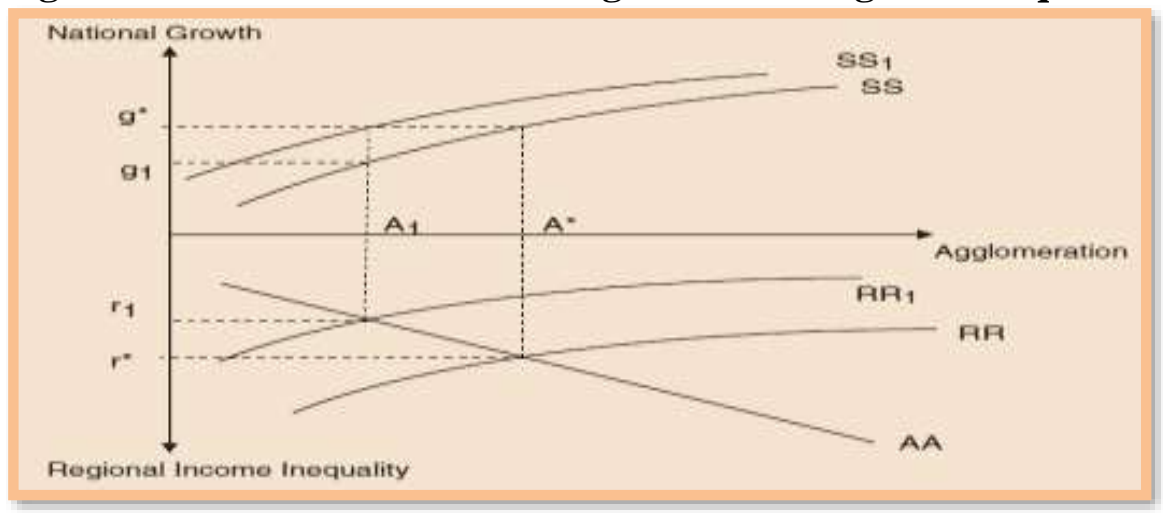

Source: Gardiner et al. 2010.

Spatial agglomeration of economic activities positively contributes in the economic growth of nation through localized positive spillovers. Agglomeration increase productivities and real output via labour pooling and knowledge spill over as shown 
from the curve SS. The equilibrium level of agglomeration, inequalities and growth comes from the intersection of two curves RR and AA. There is a tradeoff between national growth and spatial inequalities produce from agglomeration. The effective intervention of government that break up agglomeration shift RR curve to $R_{1}$ and reduces spatial inequality by the transfer of resources to poorer regions but also erase the spillover effects that results in decreasing national growth. The income of region in which economic activities clustered grow relatively at a faster rate therefore a similar trade-off became visible within regions. Therefore on the basis of NEG model it is expected that the regions that are experiencing agglomeration may undergo high income level relative to other regions.

\section{Estimation Techniques}

First the Herfindahl indices will be computed to measure the inter-temporal spatial concentration of sector. Using these indices values study will identifies regions that experience higher than average initial level of concentration and positive growth of spatial concentration.

\subsection{Measurement of Agglomeration}

Herfindahl index of spatial concentration is calculated as the sum of the regional shares in national employment in the particular industry both by industry and regions. Symbolically,

$$
\operatorname{SCR}_{\mathbf{j}}^{\mathbf{c}}=\sum_{\mathbf{i}} \mathrm{CR}_{\mathrm{ij}}^{\mathbf{c}^{2}}
$$

Where:

$\boldsymbol{C R}_{\boldsymbol{i} \boldsymbol{j}}^{\boldsymbol{c}}=$ The concentration ratio: The weight of employment in the sector i from the city $\mathrm{j}$ in the overall employment of the sector

$$
C R_{i j}^{c}=\frac{E_{i j}}{E_{i}}=\frac{E_{i j}}{\sum_{i} E_{i j}}
$$

The above index ranges from 0 to 1 . The more a region's Herfindahl index is closer to 0 the less spatially concentrated the region is, and the more it is away from 0 or closer to 1 the more it is said to be spatially concentrated.

\subsection{Measuring the linkage between spatial concentration and income}

To estimate causal treatment effects of agglomeration in exaggerating income inequalities across various regions Propensity-Score Matching (PSM) technique is used. The PSM technique was initially presented in the pioneering work of Rosenbaum and Robin (1983a, 1983b, 1985). Propensity score matching was the first time applied in the field of macroeconomics, to find the effects of currency unions on trade flow. Afterward, many economists used this technique to evaluate the causal effects in non experimental research. 
Journal of Applied Economics and Business Studies, Volume. 4, Issue 4 (2020) 187-214 https://doi.org/10.34260/jaebs.449

\section{Propensity Score Matching (PSM)}

In an experimental research randomization is assumed as there is an equal distribution of group members' characteristics for both treated and control group via random sampling and random assignments. Thus randomization limits potential selection bias therefore the only interest is to estimate cause of an effect. The observational studies lack randomization as conclusions are drawn based on data that is collected without random assignment therefore the results become inconsistent and biased. In such condition Propensity Score Matching provides the most accurate estimates of the impact.

The study employed Propensity Score Matching (PSM) to analyze the effect of agglomeration of industries on the regional income in Pakistan. For the analysis purpose regions that are experiencing increasing growth of agglomeration are treated as "Treatment Group" while the regions where agglomeration is not persistent are considered as "Control group or Counterfactuals." As we have N units (subjects or Regions). $\mathrm{C}$ denotes a treatment condition and $\mathrm{Y}$ as a potential outcome. For each unit $\mathrm{i}(\mathrm{i}=1 \ldots . . .41), \mathrm{C}_{\mathrm{i}}=1$ indicates that the subject unit is belongs to the treatment group with subsequent potential outcome $\mathrm{O}_{1 \mathrm{i}}$ and $\mathrm{C}_{\mathrm{i}}=0$ shows that the subject $\mathrm{i}$ is in counterfactual group with potential outcome $\mathrm{O}_{0 \mathrm{i}}$. To analyze causal effects in counterfactual framework the core interest is to find treatment effect for each unit i defined as

$$
\Delta_{\mathrm{i}}=\mathrm{O}_{1 \mathrm{i}}-\mathrm{O}_{0 \mathrm{i}}
$$

For each unit $\mathrm{i}, \mathrm{Y}_{1 \mathrm{i}}$ and $\mathrm{Y}_{0 \mathrm{i}}$ are not discernible at the same time because the same unit cannot simultaneously be in both the treated and untreated groups. Alternatively, Average Treatment Effects (ATE) can be estimated

$$
\mathrm{ATE}=E\left(O_{1}-\mathrm{O}_{0}\right)=E\left(O_{1}\right)-E\left(\mathrm{O}_{0}\right)
$$

The second frequently estimated effects are Average Treatment on Treated (ATT). It is the average effect of treatment on the units which are treated defined as

$$
\left.\operatorname{ATT}=\left(\mathrm{O}_{1}-\mathrm{O}_{0} \mid \mathrm{C}=1\right)=\mathrm{E}\left(\mathrm{O}_{1} / \mathrm{C}=1\right)\right]-\mathrm{E}\left(\mathrm{O}_{0} / \mathrm{C}=1\right)
$$

The ATE is the difference between average outcomes of treated group and the average outcome of untreated group, no one of which is fully observe. The estimation of $\mathrm{O}_{1}$ requires average over the outcome of treatment for treated group $\left(\mathrm{O}_{1} \mid \mathrm{C}=1\right)$ which are observed as well as average over the outcome of treatment for the untreated group $\left(\mathrm{O}_{1} \mid \mathrm{C}=0\right)$, the unobserved counterfactual. In a similar way to estimate $\mathrm{O}_{0}$ average over the outcome of non-treatment for untreated group $\left(\mathrm{O}_{0} \mid \mathrm{C}=0\right)$ and average over the outcome of non-treatment for treated group $\left(\mathrm{O}_{0} \mid \mathrm{C}=1\right)$ required, from which $\left(\mathrm{O}_{0} \mid \mathrm{C}=1\right)$ is also an unobserved counterfactual.

$$
\mathrm{ATE}=\mathrm{E}\left(\mathrm{O}_{1}-\mathrm{O}_{0}\right)=\mathrm{E}\left(\mathrm{O}_{1}\right)-\mathrm{E}\left(\mathrm{O}_{0}\right)
$$


Uzma Tabassum, Shaista Alam and Ambreen Fatima

$$
\begin{gathered}
=\left[\operatorname{Pr}(\mathrm{C}=1) \mathrm{E}\left(\mathrm{O}_{1} \mid \mathrm{C}=1\right)\right]+\left[\operatorname{Pr}(\mathrm{C}=0) \mathrm{E}\left(\mathrm{O}_{1} \mid \mathrm{C}=0\right)\right]-\left[\operatorname{Pr}(\mathrm{C}=1) \mathrm{E}\left(\mathrm{O}_{0} \mid \mathrm{C}=1\right)\right]+ \\
{\left[\operatorname{Pr}(\mathrm{C}=0) \mathrm{E}\left(\mathrm{O}_{0} \mid \mathrm{C}=0\right)\right]} \\
=\operatorname{Pr}(\mathrm{C}=1)\left[\mathrm{E}\left(\mathrm{O}_{1} \mid \mathrm{C}=1\right)-\left(\mathrm{E}\left(\mathrm{O}_{0} \mid \mathrm{C}=1\right)\right]+\operatorname{Pr}(\mathrm{C}=0)\left[\mathrm{E}\left(\mathrm{O}_{1} \mid \mathrm{C}=0\right)-\mathrm{E}\left(\mathrm{O}_{0} \mid \mathrm{C}=0\right)\right]\right.
\end{gathered}
$$

Here $\operatorname{Pr}(C=1)$ is the probability that unit is treated and $\operatorname{Pr}(C=0)$ is the probability that unit is not treated. The first part of the equation- 6 is just the proportion of units receiving the treatment multiply by the Average Treatment Effect on treatment. It is very likely in the absence of randomization that subjects' background characteristics in the two groups are significantly different which may also influence potential outcome so the present study cannot directly assess the effect of treatment without controlling for other influential factors. The unbalanced distribution influential factor between two groups may create selection which creates biased ATE. Hence, to solve the selection bias problem and evaluate the treatment effect matching adopts two postulations.

\section{Conditional Independence Assumption (CIA)}

Conditional on influential factors $\mathrm{X}, \mathrm{C}$ and $\left(\mathrm{O}_{1} \& \mathrm{O}_{0}\right)$ are independent. $\mathrm{X}$ is the vector of observed cofounders. To estimate ATT the Conditional Independence Assumption (CIA) states

\section{$\mathrm{O}_{0} \perp \mathrm{C} \mid \mathrm{X}$ or $\mathrm{O}_{0} \perp \mathrm{C} \mid \operatorname{Pr}(\mathrm{X})$}

Assumption states that there is no association among treatment and the potential outcome that arise without treatment, conditional on observable characteristics or the propensity score (Rosenbaum and Rubin; 1983). Further for estimating ATE the CIA states that conditional on observable characteristic or propensity score, treatment is independent of both treated and untreated outcomes because for the estimation of ATE treated units are required to serve as a counterfactuals for untreated units.

$$
\mathrm{O}_{1}, \mathrm{O}_{0} \mathrm{C} \mid \mathrm{X} \text { or } \mathrm{O}_{1}, \mathrm{O}_{0} \mathrm{C} \mid \operatorname{Pr}(\mathrm{X})
$$

\section{Common Support Assumption (CSA)}

A second important assumption besides independence required in matching method is the common support or overlap condition. It precludes the occurrence of perfect predictability of $\mathrm{C}$ conditional on $\mathrm{X}$. It ensures that units with the similar values of $\mathrm{X}$ possess a positive probability of being both in treated and untreated (Heckman et al; 1999). Furthermore, the common support assumption makes sure that these propensity scores must fall between 0 and 1 .

$$
0<\operatorname{Pr}(\mathrm{C}=1 \mid \mathrm{X})<1
$$

The common support assumption in strict sense can be written as

$$
0<\mathrm{c}<\operatorname{Pr}(\mathrm{C}=1 \mid \mathrm{X})<1-\mathrm{c}<1
$$


Journal of Applied Economics and Business Studies, Volume. 4, Issue 4 (2020) 187-214 https://doi.org/10.34260/jaebs.449

In a nutshell propensity score analysis set forth by Rosenbaum and Rubin (1983) ensures to reduce selection biased by balancing the distribution of observed influential characteristics (cofactors) between two groups; treated and control. Therefore PSM allow one to get unbiased estimates from observational analysis. PSM balances the allocation of observed cofactors among treated and untreated group based on resemblance of their predicted probabilities of having treatment; Propensity Scores. The PSM estimates mean effects without taking any arbitrary assumptions related to functional form and error distribution and not require parametric modeling relating subject to outcome.

\section{Estimating the Propensity Score}

For practical implementation of the propensity score two actions are required to take, one is about the model to be used for the estimation, and the other is about selection of variables that include in the model. For dichotomous dependent variable or binary treatment both logit and probit models set forth similar bounded results as compare to linear probability model that gives predictions exterior to $[0,1]$ bounds. While deciding the variable to be included for estimating of propensity score it must be kept in mind that propensity score balances the covariate across treatment status. Thus, executing matching necessitate selection of covariates $X$ that plausibly satisfy this condition. Omitting essential covariates can critically raises bias in resulting estimates (Heckman et al., 1997). Only those covariates should be included that simultaneously influence the treatment decision and the outcome variable. Further It should also be ensures that variables included in the model should not be affected by treatment or the anticipation of it. Heckman et al (1999) further indicate that the data for both groups should originate from the same resource e.g. from same questionnaire. The too good data is also not appropriate because if propensity score is either 0 or 1 for some values of $\mathrm{X}$ then conditional on those $\mathrm{X}$ values, matching would not be possible. These characteristics either never or also receive treatment. So, the common support condition not be realized and matches cannot be carried out (Kahn and Tamer; 2010). Randomization is needed to guarantee that unit with indistinguishable characteristics can be observed in two groups (Heckman et al., 1998).

\section{Selection of Matching Algorithm}

A variety of different strategies can be use to match units on their propensity scores. These method are summarize in figure- 2

\section{Figure-2 Ways to perform matching}




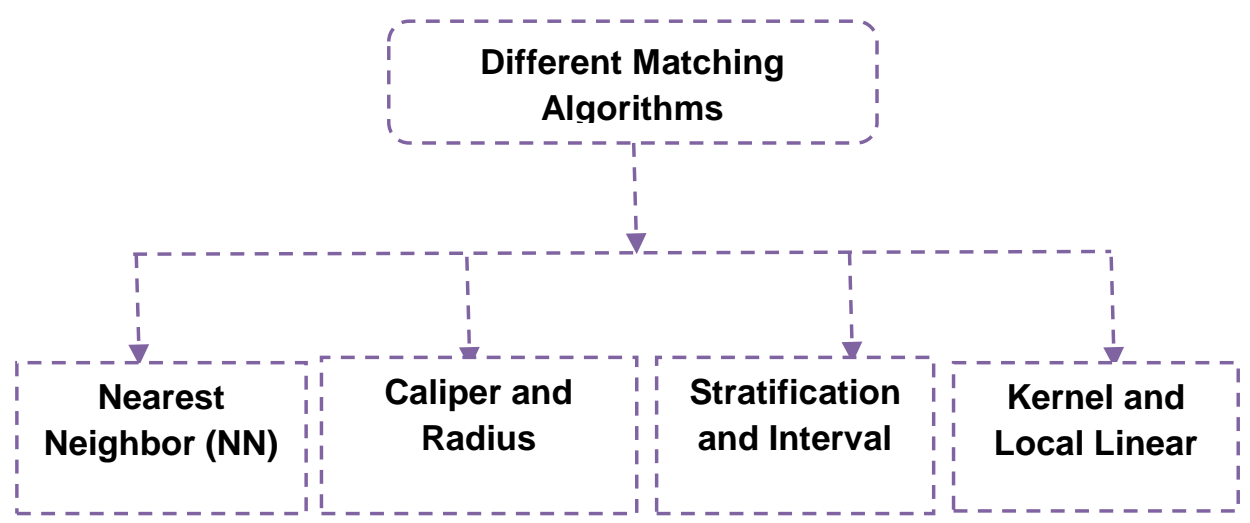

Source: Author visualization

The commonly used method of propensity score matching is nearest neighbor matching (Rosenbaum \& Rubin; 1985) that matches each unit "i" in the treatment group with a unit " $\mathrm{j}$ " in untreated group with closets absolute distance among their propensities expressed as

$$
\mathrm{D}(\mathrm{i}, \mathrm{j})=\min \left\{\mid \mathrm{P}\left(\mathrm{X}_{\mathrm{i}^{-}} \mathrm{P}\left(\mathrm{X}_{\mathrm{j}}\right) \mid\right\}\right.
$$

Alternatively, Caliper matching matches each unit " $i$ " in the treatment group with "j" in untreated group within a particular caliper band "b" (Cochran \& Rubin, 1973), stated as

$$
\mathrm{D}(\mathrm{i}, \mathrm{j})=\min \left\{\mid \mathrm{P}\left(\mathrm{X}_{\mathrm{i}}-\mathrm{P}\left(\mathrm{X}_{\mathrm{j}}\right) \mid<\mathrm{b}\right\}\right.
$$

Rosenbaum and Rubin (1985) suggested that the caliper band ought to be less than or equivalent to 0.25 of the Standard deviation of propensity score. Later Austin (2011) suggested that the optimal value of b should be 0.20 . Dehejia \& Wahba (2002) proposed the idea of radius matching which matches each unit "i" in the treated group with multiple units in untreated group within a particular band

$$
\mathrm{D}(\mathrm{i}, \mathrm{j})=\min \left\{\mid \mathrm{P}\left(\mathrm{X}_{\mathrm{i}^{-}} \mathrm{P}\left(\mathrm{X}_{\mathrm{j}}\right) \mid<\mathrm{b}\right\}\right.
$$

In the strategy of stratification matching or interval matching the common support of propensity score is alienated into a set of interval. The impact within each intermission is measured by computing the mean difference in potential outcomes between treated and untreated (Rosenbaum and Rubin; 1983). Under the normality the use of five intervals are often enough to remove $95 \%$ of the biasness associated with covariates (Cochrane and Chambers; 1965 and Imbens; 2004).Kernel matching and local linear matching are non-parametric matching estimators. In kernel matching weighted averages of all units in the control group are utilized to create the ten counterfactual outcomes. Weights rely on the extent with which each treated unit is farther from the untreated group and the accomplice observation for which the counterfactual is estimated. 
This study employ the most commonly used matching strategy Nearest Neighbor $(N N)$ matching. Differences are attained after matching the entire treated unit with control units and come up with ATT by averaging these differences. This kind of matching can be performed with or without replacement. When the matching is done with replacement (one nearest neighbor) it curtails biasness but enlarge the variance. In contrast, matching with more nearest neighbors inflate biasness but reduces the variability. The general formula of ATT is

$$
\left.\mathrm{ATT}=\left(\mathrm{O}_{1}-\mathrm{O}_{0} \mid \mathrm{C}=1\right)=\mathrm{E}\left(\mathrm{O}_{1} \mid \mathrm{C}=1\right)\right]-\mathrm{E}\left(\mathrm{O}_{0} \mid \mathrm{C}=1\right)
$$

Using Nearest Neighbor (NN) matching ATT is estimated as

$$
\begin{aligned}
& \mathrm{ATT}^{\mathrm{NN}}=\frac{1}{N^{C}} \sum_{\mathrm{i}: w \mathrm{i}=1}\left[O_{i}{ }^{o b s}-\sum_{j \in C(i) M} W_{i j} O_{i j}{ }^{o b s}\right] \\
& =\frac{1}{{ }^{C} C} \sum_{i: w i=1} O_{i}^{o b s}-\frac{1}{N^{T}} \sum_{j \in C(i) M} W_{j} O_{i j}{ }^{o b s}
\end{aligned}
$$

$\mathrm{N}^{\mathrm{C}}$ indicate the no. of observations in the treated group

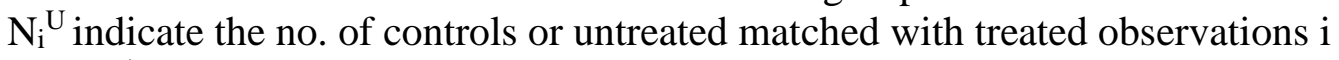

$\mathrm{W}_{\mathrm{ij}}=\frac{1}{{ }^{U}}$ if $\mathrm{j}$ is a control unit of $\mathrm{i}$ and 0 otherwise and $\mathrm{W}_{\mathrm{j}}=\sum_{\mathrm{i}} \mathrm{W}_{\mathrm{ij}}$

$\mathrm{C}(\mathrm{i})_{\mathrm{M}}$ indicate the set of first $\mathrm{M}$ matches for unit $\mathrm{i}$

\section{Empirical Findings}

Regions experiencing positive growth of agglomeration and above-average level of agglomeration in most recent period 2017-18 are listed in Table-1.The results are obtained using LFS data for the period 2010 to 2018. For this time span only eight of the 40 urban regions fulfilled both criteria necessary to qualify as a 'Treated regions.

Table-1: Summary statistics of Herfindahl-Hirschman Index (HHI)

\begin{tabular}{lccc} 
Urban Districts & $\begin{array}{c}\text { Agglomeration } \\
\text { Growth from 2010 }\end{array}$ & $\begin{array}{c}\text { in 2018 Above } \\
\text { average }\end{array}$ & $\begin{array}{c}\text { Matching positive } \\
\text { growth \& above } \\
\text { average }\end{array}$ \\
\hline Peshawar L & $\mathrm{X}$ & $\checkmark$ & $\mathrm{X}$ \\
\hline Rawalpindi & $\mathrm{X}$ & $\checkmark$ & $\mathrm{X}$ \\
\hline Sargodha L & $\mathrm{X}$ & $\mathrm{X}$ & $\mathrm{X}$ \\
\hline FaisalabadL & $\mathrm{X}$ & $\checkmark$ & $\mathrm{X}$ \\
\hline Gujranwala L & $\checkmark$ & $\checkmark$ & $\square$ \\
\hline Sialkot L & $\checkmark$ & $\checkmark$ & $\square$ \\
\hline Lahore L & $\checkmark$ & $\checkmark$ & $\square$ \\
\hline Multan L & $\checkmark$ & $\checkmark$ & X \\
\hline Bahawalpur L & $\mathrm{X}$ & $\mathrm{X}$ & $\mathrm{X}$ \\
\hline Sukkur L & $\checkmark$ & $\mathrm{X}$ & $\mathrm{X}$ \\
\hline HyderabadL & $\mathrm{X}$ & $\checkmark$ & $\mathrm{X}$ \\
\hline Karachi L & $\mathrm{X}$ & $\checkmark$ & $\mathrm{X}$ \\
\hline Quetta L & $\mathrm{X}$ & $\mathrm{X}$ & $\mathrm{X}$
\end{tabular}


Uzma Tabassum, Shaista Alam and Ambreen Fatima

\begin{tabular}{|c|c|c|c|}
\hline Urban Districts & $\begin{array}{l}\text { Agglomeration } \\
\text { Growth from } 2010\end{array}$ & $\begin{array}{c}\text { in } 2018 \text { Above } \\
\text { average }\end{array}$ & $\begin{array}{c}\text { Matching positive } \\
\text { growth \& above } \\
\text { average }\end{array}$ \\
\hline Malakand & $\checkmark$ & $\mathrm{X}$ & $\mathrm{X}$ \\
\hline Hazara & $\checkmark$ & $\mathrm{X}$ & $\mathrm{X}$ \\
\hline Mardan & $\mathrm{X}$ & $\mathrm{X}$ & $\mathrm{X}$ \\
\hline Peshawar & $\checkmark$ & $\mathrm{X}$ & $\mathrm{X}$ \\
\hline Kohat & $\mathrm{X}$ & $\mathrm{X}$ & $\mathrm{X}$ \\
\hline Bannu & $\checkmark$ & $\mathrm{X}$ & $\mathrm{X}$ \\
\hline D I Khan & $\mathrm{X}$ & $\mathrm{X}$ & $\mathrm{X}$ \\
\hline Rawalpindi & $\checkmark$ & $\checkmark$ & $\nabla$ \\
\hline Sargodha & $\mathrm{X}$ & $\mathrm{X}$ & $\mathrm{X}$ \\
\hline Faisalabad & $\checkmark$ & $\checkmark$ & $\nabla$ \\
\hline Gujranwala & $\checkmark$ & $\checkmark$ & $\bar{\nabla}$ \\
\hline Lahore & $\mathrm{X}$ & $\checkmark$ & $\mathrm{X}$ \\
\hline Multan & $\mathrm{X}$ & $\checkmark$ & $\mathrm{X}$ \\
\hline DG Khan & $\checkmark$ & $\checkmark$ & V \\
\hline Bahawalpur & 0 & $\checkmark$ & $\mathrm{X}$ \\
\hline Larkana & 0 & $\checkmark$ & $\mathrm{X}$ \\
\hline Sukkar & 0 & $\checkmark$ & $\mathrm{X}$ \\
\hline Hyderabad & 0 & $\checkmark$ & $\mathrm{X}$ \\
\hline Mirpurkhas & 0 & $\mathrm{X}$ & $\mathrm{X}$ \\
\hline Quetta & $\checkmark$ & $\mathrm{X}$ & $\mathrm{X}$ \\
\hline Zhob & $\checkmark$ & $\mathrm{X}$ & $\mathrm{X}$ \\
\hline Sibbi & $\checkmark$ & $\mathrm{X}$ & $\mathrm{X}$ \\
\hline Nasirabad & $\checkmark$ & $\mathrm{X}$ & $\mathrm{X}$ \\
\hline Qalat & $\checkmark$ & $\mathrm{X}$ & $\mathrm{X}$ \\
\hline Makran & $\checkmark$ & $\mathrm{X}$ & $\mathrm{X}$ \\
\hline
\end{tabular}

Source: Authors' own Calculation based on Herfindahl index

After identifying the treated and untreated regions the second step is to estimate causal treatment effects of agglomeration on regions income that responsible to exaggerate inequalities across treated and untreated regions. As stated earlier for this purpose Propensity-Score Matching (PSM) technique is used.

Based on the hypothesis to be tested, Number of covariates appears to be critical for this research. These covariates include the demographics of the household resides in the regions which are spatially concentrated, the knowledge and education variables. In addition with other categorical variables such as migrant or non migrant household, occupation and non categorical labour market variables such as female participation in the labour market, no of work hours etc all these variables expected to influence the average income of the household.

The comparison of covariates across treated and untreated subject can be done by comparing the mean or median of continuous variables and the allocation of categorical 200 
variables among these two groups. For this purpose the standardized difference (SD) can be used. The standardized difference evaluates the variation in means in units of the pooled standard deviation (Flury \& Riedwyl; 1986). For continuous variable the SD is measured as:

$$
S D_{\text {con }}=\frac{\bar{X}_{\text {treated }}-\bar{X}_{\text {control }}}{\sqrt{\frac{S_{\text {treated }}^{2}+S_{\text {control }}^{2}}{2}}}
$$

Where $\bar{X}_{\text {treated }} \& \bar{X}_{\text {control }}$ are the sample mean of continuous variables in treated and untreated groups respectively, $S_{\text {treated }}^{2} \& S_{\text {control }}^{2}$ are the sample variance in both groups. For dichotomous variables SD is measured as:

$$
S D_{\text {dicho }}=\frac{\widehat{\mathrm{P}}_{\text {treated }}-\widehat{\mathrm{P}}_{\text {control }}}{\sqrt{\frac{\widehat{\mathrm{P}}_{\text {treated }} *\left(1-\widehat{\mathrm{P}}_{\text {treated }}\right)+\widehat{\mathrm{P}}_{\text {control }} *\left(1-\widehat{\mathrm{P}}_{\text {control }}\right)}{2}}}
$$

Where $\widehat{\mathrm{P}}_{\text {treated }} \& \widehat{\mathrm{P}}_{\text {control }}$ are the occurrence of dichotomous variable in treated and untreated group. SMD is not influenced by sample size and allow comparison of the variables measured in different units. Less than 0.1 value of SMD indicates aim perceptible difference in mean or prevalence of variables between two groups (Normand et al; 2001). The below table shows the "Standardized Difference (SD)" - the difference in term of Standard error of some of demographic variables in treated and untreated group. The result shows that the treated and untreated differ by about $-0.24 \mathrm{SD}$ in dependency ratio, dependency ratio is higher in the untreated regions than the regions that are experiencing concentration. Education and age of highest earner in treated and untreated differ by 0.12 SD while the age of head of household is more similar in treated and untreated as SD is about 0.08. Significant difference appears in average years of schooling that is about $0.37 \mathrm{SD}$.

Table-2 Standardized Differences in Selected demographic Variables

\begin{tabular}{l|c|c|c} 
& Mean in treated & Mean in Untreated & Standardised diff. \\
\hline Dependency Ratio & 2.87 & 3.39 & -0.24 \\
\hline Average Education & 8.25 & 7.15 & 0.37 \\
\hline Education of Highest Earner & 5.9 & 5.45 & 0.12 \\
\hline Age of highest earner & 37.25 & 35.84 & 0.12 \\
\hline Age of HOH & 48.25 & 47.17 & 0.08 \\
\hline
\end{tabular}

Source: Authors calculations based on LFS 2017-18

The standardized difference in selected binary variable such as gender of head of household and gender of highest earner is quite negligible but the proportion of migrant household in treated group is quite differ than comparative group as the value of SD is about 0.26 . 
Uzma Tabassum, Shaista Alam and Ambreen Fatima

\begin{tabular}{l|c|c|c}
\hline \multicolumn{3}{c}{ Table-3 Standardized Differences in Selected dichotomous Variables } \\
\hline & $\begin{array}{c}\text { Proportion in } \\
\text { treated }\end{array}$ & $\begin{array}{c}\text { Proportion in } \\
\text { Untreated }\end{array}$ & $\begin{array}{c}\text { Standardised } \\
\text { diff. }\end{array}$ \\
\hline Migration & 0.20 & 0.11 & 0.26 \\
\hline $\begin{array}{l}\text { Gender of HOH (Male) } \\
\text { Gender of Highest Earner } \\
\text { (Male) }\end{array}$ & 0.91 & 0.94 & -0.09 \\
\hline
\end{tabular}

Source: Authors calculations based on LFS 2017-18

The standardized difference in labour market related variables shows that percentage of females participate in labour market both in treated and untreated group differ by about -0.21 SD. Female in untreated group participate more in labour market than the female resides in spatially agglomerated regions. The individuals belongs to the household located in treated regions are technically more sound and the standardized difference is about 0.32 between treated and untreated group. The average weekly hours work is differ by $0.4 \mathrm{SD}$, households resides in spatially concentrated regions weekly works more hours than the comparative group. There is a negligible difference (0.06 SD) in working age population between treated and untreated regions.

Table-4 Standardized Differences in Labour Market Variables

\begin{tabular}{l|c|c|c} 
& $\begin{array}{c}\text { Mean in } \\
\text { treated }\end{array}$ & $\begin{array}{c}\text { Mean in } \\
\text { Untreated }\end{array}$ & $\begin{array}{c}\text { Standardised } \\
\text { diff. }\end{array}$ \\
\hline Female participation Ratio & 0.14 & 0.21 & -0.218 \\
\hline $\begin{array}{l}\text { \% of Technically trained working } \\
\text { age individuals in HIH }\end{array}$ & 0.26 & 0.17 & 0.322 \\
\hline Working age population & 3.84 & 3.71 & 0.062 \\
\hline A verage weekly hours works & 51.26 & 45.81 & 0.401 \\
\hline
\end{tabular}

Source: Authors calculations based on LFS 2017-18

The figure-3 demonstrates the outcome variable-average income of the household from the districts where spatial concentration is observed during the considered time span and the average income of the household from the districts that are spatially disbursed. It is visible from the figure that the households living in those urban regions which are experiencing agglomeration enjoys high level of per-capita income in contrast to those household which are living in regions where concentration is not high and persistent.

Figure-3: Average income of household in treated and untreated region 


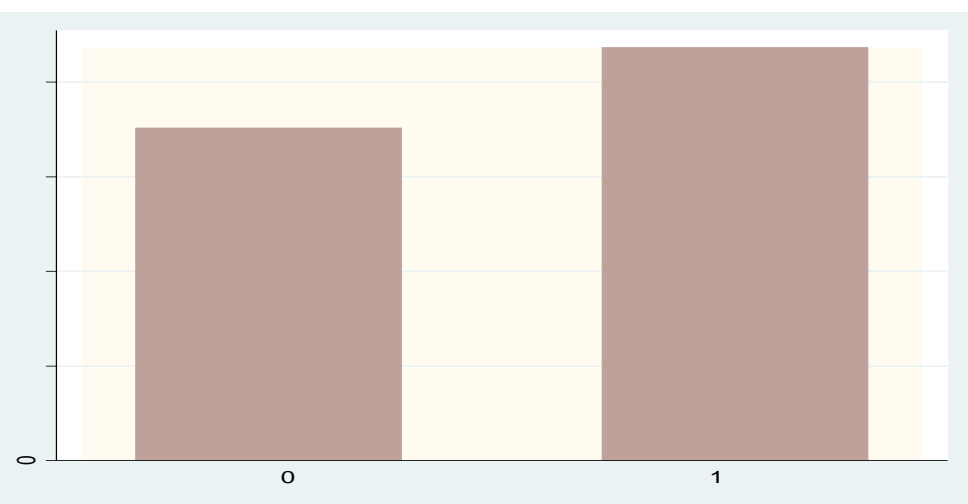

Source: Authors visualization based on LFS 2017-18

Next Figure also shows significant difference in average income of household resides in spatially concentrated urban regions and the regions where such concentration is not quite visible. The largest part of the data points are either overlap the diagonal or to the left of the diagonal that shows that the values of the distribution on the y-axis are higher than those of the distribution on the $\mathrm{x}$-axis means income of the household reside in agglomerated region is much higher than the income of the households that reside in the regions which does not fulfill the criteria to be called agglomerated. It can also be observed that income inequality is somewhat stronger for higher income but it is quite weak for lower income.

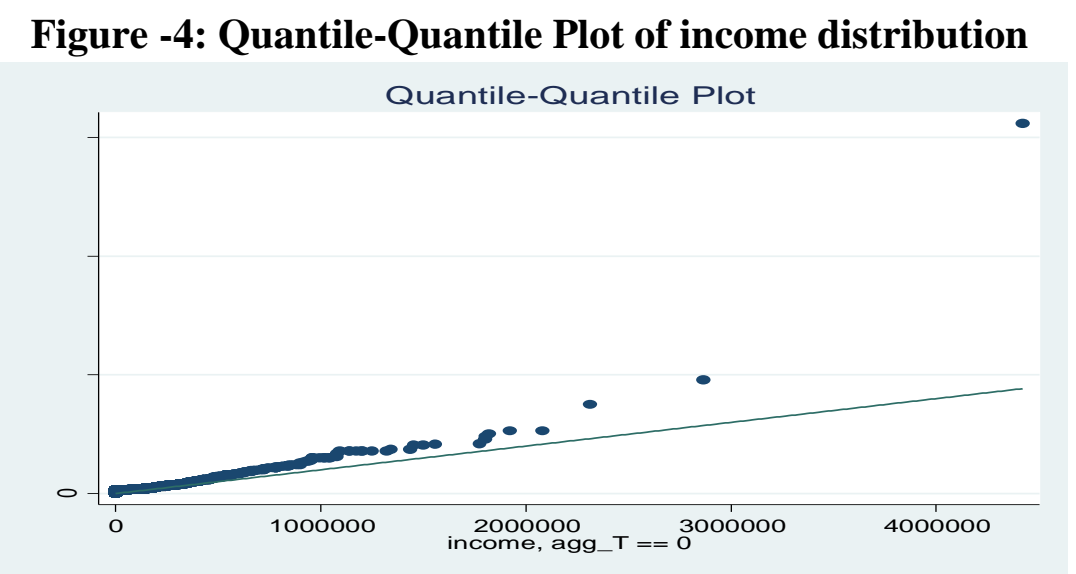

Source: Authors visualization based on LFS 2017-18

\section{Estimation of Propensity Score}

The estimates of probit models are used to estimates the propensity scores based on which the matching is done afterward. The probit model provides the probabilities or propensities to calculate the average treatment effect of spatial concentration on the average income of household resides in these regions. 
To estimates the propensities the dichotomous treatment variable -spatial concentration run on the covariates selected however, the estimates of the probit model are just to predict the propensities and hence not provide any meaning full explanation. The study has first estimated probability of receiving treatment by regressing binary variable agglomeration equals 1 if regions spatial concentration is above average in base period and with positive growth and 0 otherwise as a function of household characteristics including average education, age \& gender of head of household, age and education of highest earner, dependency ratio, Female participation Ratio, Percentage of technically trained working age individuals in household, Average weekly hours works and Provincial and occupational dummies. The probability of receiving treatment is positively correlated with Average schooling, age of highest earner and head of household, migrant household, male headed household, no of working age individuals in household, Average weekly hours works, Percentage of Technically trained working age individuals in household and negatively correlated with age of head of household, education of highest earner, dependency ratio and female participation rate. Almost all variables are significant, except some occupational and regional dummies. The results as stated above are annexed (see Table A1). Overall, the model is statistically fit on the basis of the likelihood chi-square. For the estimation of PS, 18,722 observations that fall within the common support region [.002032, .8526713] have been used (see Annex Table-A2).

\section{Common Support or Overlap Condition}

It is essential to test out the common support region for the both treated and untreated group. If the distribution does not overlap it would be problematic but using the minimum and maximum comparison the problem could be tackled. To do this all those observation that has propensity score smaller than minimum or larger than the maximum would be deleted. Hence all those observations are withdrawn from the analysis that comes into view outside the common support region. Table-5 shows the number of observation removed from the analysis on the basis of nearest neighbor matching. The number of removed observation is quite low in this case only 3 observations have been removed from the analysis that appeared off support.

Table 5: Common Support Condition for Nearest Neighbor

\begin{tabular}{cccc} 
psmatch2 Treatment & \multicolumn{3}{c}{ psmatch2 common } \\
\cline { 2 - 4 } Assignment & off support & on support & Total \\
\hline Untreated & 0 & 14,036 & 14,036 \\
\hline Treated & 3 & 4,683 & 4,686 \\
\hline Total & 3 & 18,719 & 18,722 \\
\hline
\end{tabular}

Source: Author's estimations based on LFS 2017-18.

A description of the density distribution of propensity score can be seen in figure-1. The upper part of the figure shows propensity score distribution for treated, whereas the below part of the figure refers to the treated. The symmetric distribution of the covariates after the matching indicates the overlapping of the treated and non-treated groups and hence it is concluded that the common support condition is satisfied.

204 
Figure-5: Distribution of Propensity Score to test Quality of Matching among Treated and Untreated Groups

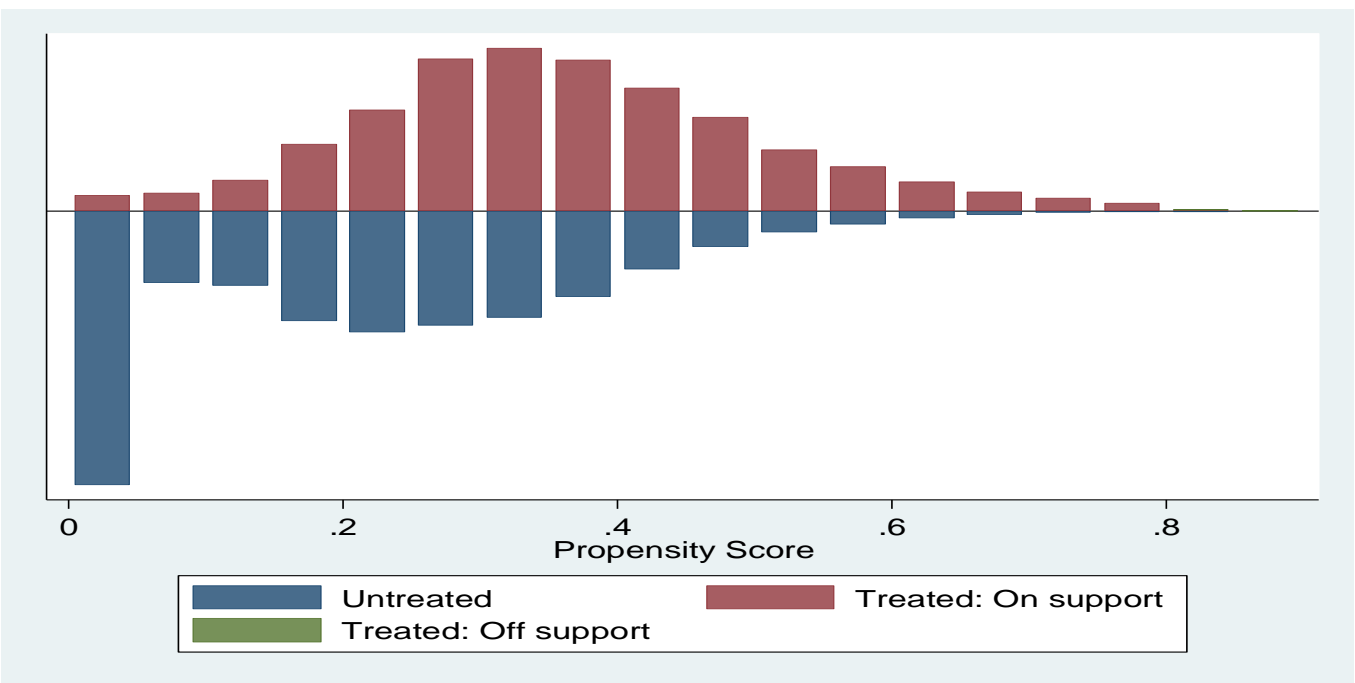

Source: Author's estimations based on LFS 2017-18.

\section{Effects of Spatial Concentration on Average Income:}

This research work has empirically tested that concentration of industries at particular region has positive impact on the livelihood of household resides in these regions. The role of spatial concentration in raising livelihood by positively affect income of the household is proved valid. The empirical result of Average treatment effect of the spatial concentration on income level of household is reported in table- 6 . Statistically significant and positive coefficient indicated that the one percent increase in spatial concentration raises income level of the households that reside in these urban districts of Pakistan by 346854.

Table-6: Average Treatment Effects of Agglomeration on Income

\begin{tabular}{ccccc} 
Matched/Unmatched & Treated & Controls & Difference & T-stat \\
\hline Unmatched & 12.75 & 12.38 & .374 & 27.07 \\
\hline ATT & 12.76 & 12.55 & .203 & 9.09 \\
\hline
\end{tabular}

Source: Author's estimations based on LFS 2017-18.

The positive and statistically significant value of average treatment effect of unmatched group (ATT) shows that on average, income of household increased by $\left[\left(\mathrm{e}^{0.374}-1\right) * 100=45.4 \%\right]$ for $2017-18$. Further, the positive and statistically significant value of the average treatment effect on treated (matched ATT) shows that income of household increased by $\left[\left(\mathrm{e}^{0.20335}-1\right)=22.55 \%\right]$. 
Uzma Tabassum, Shaista Alam and Ambreen Fatima

\section{Quality of Matching}

The study carried out t-tests to evaluate either difference between treated and nontreated groups are statistically significant or not. Once the balance is attained with PSM, tstatistic turns out to be statistically insignificant because there is negligible difference between treated and non-treated. In this regards, the covariates' variance ratios of the treated over the untreated measures are also estimated. The ratio should be equal to one if there is perfect balance across samples. All these measures provide portent of whether particular covariates are balanced across treated and non-treated groups. The results indicate that before matching most of the variables have demonstrated statistically significant differences but after matching most of the covariates found balanced and no significant statistical differences have been found ${ }^{1}$.Further the Table- 7 indicates that the bias percentage for each of the covariate is also reduced significantly after applying matching.

Table-7 Covariates Balancing Test (PS-test)

\begin{tabular}{|c|c|c|c|c|c|c|c|}
\hline \multirow[t]{2}{*}{ Variable } & \multirow[t]{2}{*}{$\begin{array}{c}\text { Unmatched/ } \\
\text { Matched }\end{array}$} & \multicolumn{2}{|c|}{ Mean } & \multicolumn{2}{|c|}{ \% Reduction } & \multirow{2}{*}{$\frac{\text { t-test }}{T}$} & \multirow[t]{2}{*}{$\mathrm{V}(\mathrm{T}) / \mathrm{V}(\mathrm{C} 1)$} \\
\hline & & Treated & Control & \%bias & Bias & & \\
\hline \multirow{2}{*}{ Female participation Rate } & $\mathrm{U}$ & 0.138 & 0.213 & -21.8 & \multirow{2}{*}{74} & -30.26 & $0.63 *$ \\
\hline & $M$ & 0.258 & 0.239 & 5.7 & & 2.58 & 1.03 \\
\hline \multirow{2}{*}{ Gender of the Head - Male } & $\mathrm{U}$ & 1.084 & 1.059 & 9.8 & \multirow{2}{*}{77.3} & 16.08 & $1.39 *$ \\
\hline & $\mathrm{M}$ & 1.077 & 1.071 & 2.2 & & 1.06 & $1.07 *$ \\
\hline \multirow{2}{*}{$\begin{array}{l}\text { Working age members in } \\
\text { household }\end{array}$} & $\mathrm{U}$ & 3.841 & 3.713 & 6.2 & \multirow[b]{2}{*}{-70.7} & 9.35 & $0.94 *$ \\
\hline & M & 4.472 & 4.254 & 10.6 & & 5.23 & $1.12 *$ \\
\hline \multirow{2}{*}{$\begin{array}{c}\text { Education of the Highest } \\
\text { Earner }\end{array}$} & $\mathrm{U}$ & 5.631 & 4.897 & 19.5 & \multirow{2}{*}{93.1} & 23.33 & $1.09 *$ \\
\hline & M & 5.731 & 5.781 & -1.3 & & -0.66 & $1.08 *$ \\
\hline \multirow{2}{*}{ Age of the Highest Earner } & $\mathrm{U}$ & 37.07 & 35.59 & 12.6 & \multirow{2}{*}{97.8} & 15.07 & $1.06 *$ \\
\hline & $\mathrm{M}$ & 36.27 & 36.30 & -0.3 & & -0.12 & 0.95 \\
\hline \multirow{2}{*}{$\begin{array}{c}\text { Technical/Vocational } \\
\text { training }\end{array}$} & $\mathrm{U}$ & 0.253 & 0.166 & 30.9 & \multirow{2}{*}{99.4} & 50.06 & $1.32 *$ \\
\hline & M & 0.285 & 0.285 & 0.2 & & 0.09 & 1.05 \\
\hline \multirow{2}{*}{ Average hours work } & $\mathrm{U}$ & 52.061 & 47.177 & 42.8 & \multirow{2}{*}{96.2} & 62.69 & $0.95 *$ \\
\hline & $\mathrm{M}$ & 49.668 & 49.851 & -1.6 & & -0.86 & $0.79 *$ \\
\hline \multirow{2}{*}{ A verage schooling } & $\mathrm{U}$ & 8.203 & 6.806 & 48.5 & \multirow{2}{*}{99} & 71.9 & 1 \\
\hline & $\mathrm{M}$ & 8.263 & 8.278 & -0.5 & & -0.23 & 1.01 \\
\hline \multirow{2}{*}{ Migrant HOH } & $\mathrm{U}$ & 1.166 & 1.089 & 33 & \multirow{2}{*}{99.3} & 56.51 & $1.68 *$ \\
\hline & $\mathrm{M}$ & 1.178 & 1.179 & -0.2 & & -0.1 & 1.05 \\
\hline \multirow{2}{*}{ Dependency ratio } & $\mathrm{U}$ & 3.189 & 3.448 & -11.5 & \multirow{2}{*}{45.1} & -15.82 & $0.67 *$ \\
\hline & $\mathrm{M}$ & 2.091 & 2.234 & -6.3 & & -4.26 & $0.94 *$ \\
\hline \multirow{2}{*}{ Age of $\mathrm{HOH}$} & $\mathrm{U}$ & 47.15 & 45.826 & 10.3 & \multirow{2}{*}{70.3} & 15.62 & 0.95 \\
\hline & $\mathrm{M}$ & 48.863 & 48.47 & 3.1 & & 1.52 & 1.03 \\
\hline
\end{tabular}

*if variance ratio outside $[0.98 ; 1.02]$ for $\mathrm{U}$ and $[0.94 ; 1.06]$ for $\mathrm{M}$

Source: Author estimation using LFS-2017-18

The absolute percentage bias for treatment and the control group before and after the matching are presented in the table-8. It can be observed from the table that the absolute mean bias has reduced from 18.8 to 1.6 percent and absolute median bias reduced from 9.2 to 1.2 percent for the year 2017-18 after performing the PSM. Also,

${ }^{1}$ occupational and provincial dummies were included in pstest and also found statistically insignificant 206 
after matching Pseudo $\mathrm{R}^{2}$ is reduced significantly from 0.21 to 0.003 . Insignificant $\mathrm{p}$ value of likelihood ratio after matching implies that estimation of the propensity score matching is efficient regarding balancing the distribution of covariates between two groups. So, on the basis of the measures presented it can be concluded the (Nearest Neighbor) Propensity score matching is an efficient method to construct a similar control group and to estimate the average treatment effect.

Table-8 Average percentage bias

\begin{tabular}{cccccc} 
Sample & Ps R $^{2}$ & LR chi $^{2}$ & p $>$ chi $^{2}$ & Mean Bias & Med Bias \\
\hline Unmatched & $\mathbf{0 . 2 1 5}$ & 3143.96 & 0.000 & 18.8 & 9.2 \\
\hline Matched & $\mathbf{0 . 0 0 3}$ & 43.05 & 0.555 & 1.6 & 1.2 \\
\hline
\end{tabular}

Source: Author estimation using LFS-2017-18

The graph indicates how individual variables balance after matching. The $\mathrm{x}$-axis displays the standardized bias, which is the percentage difference of the sample means in the treated and non-treated as a percentage of the square root of the average of the sample variances in the treated and non-treated groups (Rosenbaum and Rubin; 1985)

Figure-6 Standardized bias across covariates

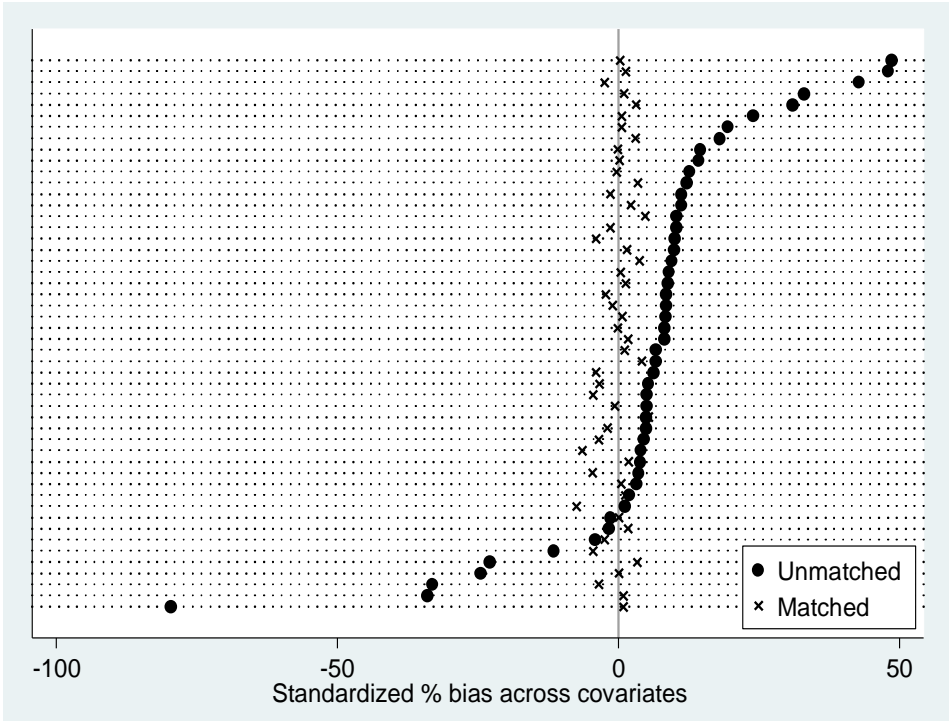

Source: Author estimation using LFS-2017-18

It can be visualized from figure that the unmatched sample exhibit large imbalances with standardized bias being present across many of covariates but once the matching is done the standardized differences diminished significantly. Further the same results can also be seen through the histogram. It can be observed that the standardized 
percentage bias has reduced significantly after the matching. Comparing the upper panel which shows the percentage bias in unmatched (non-treated group) with the second panel reveals significant reduction in percentage bias after the matching.

Figure-7 Histogram of Standardized \% Bias

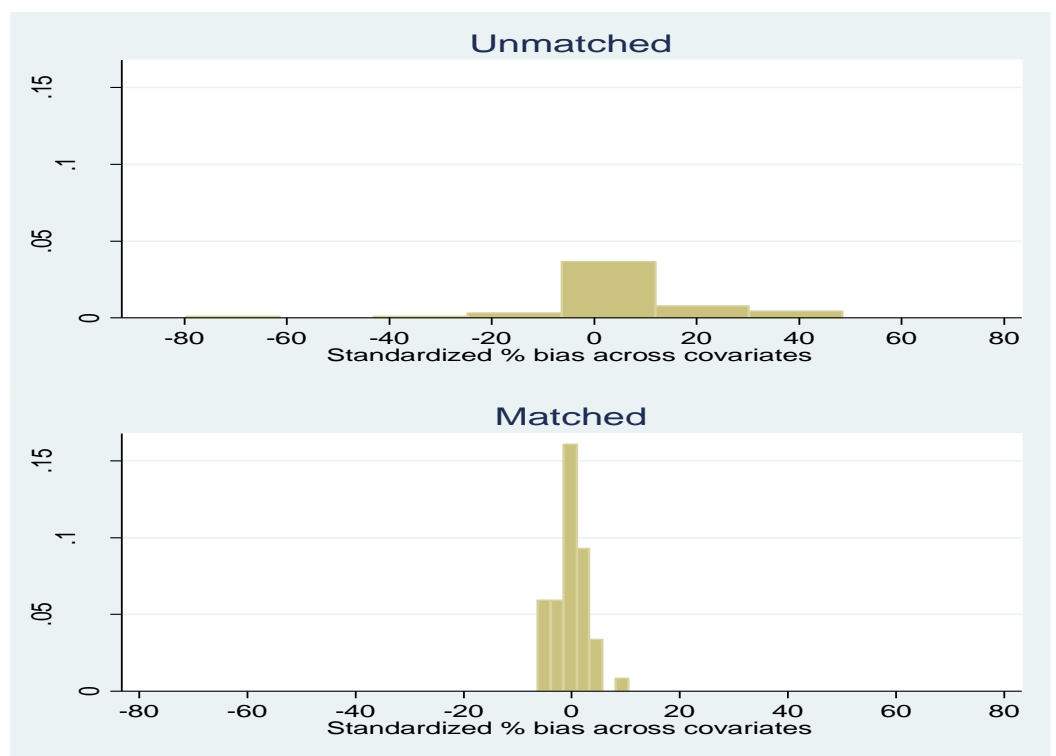

Source: Author estimation using LFS-2017-18

\section{Conclusion and Policy Implications}

The purpose of this research is to explore the variation of spatial concentration lagglomeration across urban districts of Pakistan and analyses the effect of this concentration on the prevalence of income inequalities. The basic view is that spatial concentration amplifies inequalities across regions, because of the differences in productivity. The empirical literatures on the spatial disparities between urban regions based on agglomeration are rather scarce. This study attempts to start bridging this gap by using survey data conducted by Pakistan Bureau of Statistics (PBS). The empirical results and the evidences provided clearly indicate that distribution of income is significantly affected by spatial concentration supports the viewpoint of New Economic Geography (NEG) model. As per New Economic Geography (NEG) model the economic activities will be higher in the region of increased agglomeration which results in spatial inequalities showing the positive inter relation. To reveal results this study used two steps methodology. First the Herfindahl indices have computed, using Labour Force Survey (LFS) for the year 2010 to 2018, to measure the inter-temporal spatial concentration of industries. Using the values of indices urban regions are identified that have positive and above average level of concentration. Four large cities, Gujranwala, Sialkot, Lahore, Multan and four other urban areas Rawalpindi, Faisalabad, Gujranwala 
and DG Khan fulfilled both criteria. After identifying the agglomerated regions the second step was to estimate causal treatment effects of agglomeration on regions income that responsible to exaggerate inequalities across agglomerated and non agglomerated regions. Propensity-Score Matching (PSM) was applied for this purpose. For the analysis eight regions that are experiencing increasing growth of agglomeration was considered as "Treated Group" while the regions where agglomeration appeared non persistent was considered as "Control Group." The statistically significant coefficient of average treatment effect on treated (ATT) with positive sign indicated that the one percent increase in spatial concentration increase income level of the households that reside in these urban districts of Pakistan by 346854. Further no significant statistical differences have been found after matching and most of the covariates found balanced as per ps-test results. After performing PSM absolute percentage bias also decrease significantly. The absolute mean bias has reduced from 18.8 to 1.6 percent and absolute median bias reduced from 9.2 to 1.2. In a nut shell, it can be concluded that agglomeration is important determinant of regional variations in income. The reported findings have significant implications for regional policy. It means that obstructing the agglomeration of industries with the intention of encouraging equality may hurts productivity. In order to lessen spatial income inequalities focusing on the development of regional agglomeration of activities, rather than dispersion of resources to every single region, seems to be the correct way to carry on. The effective policies to promote agglomeration are needed for growing urban population that has the potential to turn out to be an effective part of economic growth. Pakistan fronting many challenges; Key to this is the provision of employment to growing labour force and create vibrant industrial sector that can provide variety of jobs requiring skills of different intensity. In the absences of such opportunities the standard of living for those that are affected abated which may lead social unrest. There is also need to improve infrastructure in order to promote agglomeration and greater inclusion and equity.

\section{References}

Abid A. Burki\& Mushtaq A. Khan (2011). "Agglomeration Economies and their Effects on Technical Inefficiency of Manufacturing Firms: Evidence from Pakistan", International Growth Centre Working paper

Aiginger, K. \&Rossi-Hansberg, E. (2006). "Specialization and Concentration: a note on theory and evidence" Empirica 33, pp. 255-266.

Aiginger, K. (1999) "Do Industrial Structures Converge? A survey on the empirical literature on specialization and concentration of industries", WIFO-Working papers.

Aiginger, K., Davies, D. (2004). "Industrial Specialization and Geographical Concentration; Two sides of the same coin?" Journal of Applied Economics 7(2), pp. 231-248. 
Austin P.C. (2011) "A tutorial and case study in propensity score analysis: An application to estimating the effect of in-hospital smoking cessation counseling on mortality". Multivariate Behavioral Research, 46 pp. 119-151.

Azhar, A. \& Adil, S. (2016). " Effect of Agglomeration on Socio-Economic Outcomes: A District Level Panel study of Punjab" The Pakistan Development Review Papers and Proceedings: The 32nd Conference of the Pakistan Society of Development Economists, December 13 - 15, 2016, pp. 155-170

Burki, A. A \& Khan, A. M. (2012). "Agglomeration Economies and their Effects on Technical Inefficiency of Manufacturing Firms: Evidence from Pakistan", International Growth Centre Working paper

Chaudhry, A., \& Haroon, M. (2015). "The Economic Impact of New Firms in Punjab". The LahoreJournal of Economics 20, pp. 143-182

Cochran, W. G., \& Rubin D. B. (1973). "Controlling Bias in Observational Studies: A Review," Sankhya, The Indian Journal of Statistics, 35(4), pp.417-446.

Cochrane, W., and S. Chambers (1965). "The Planning of Observational Studies of Human Populations," Journal of the Royal Statistical Society, Series A, 128, pp. 234-266.

Daytyan, K. (2016). "Interrelation among Economic Growth, Income Inequality, and Fiscal Performance: Evidence from Anglo-Saxon Countries," Review of Public Economics, vol 217(2), pp 37-66.

Dehejia, R. H., and S. Wahba (2002), "Propensity Score Matching Methods for Nonexperimental Causal Studies," Review of Economics and Statistics, 84, pp. $151-161$.

Duranton, G., Puga, D. (2004). "Micro-foundations of urban agglomeration economies.” In: Henderson, J.V., Thisse, J.-F. (Eds.), Handbook of Urban and Regional Economics, Vol. 4, North-Holland, Amsterdam, pp. 2063-117.

Ellison, G., E. Glaeser (1997). "Geographic Concentration in U.S. Manufacturing Industries: A Dartboard Approach", Journal of Political Economy, 105, pp. 889927.

Fambon, S. (2017) "The Determinants of Inequality and Income Gap between Urban and Rural Areas in Cameroon: Evidence from the ECAM3 Household Survey". Advances in Economics and Business, 5(7), pp.394 - 410.

Fan, C., and A. Scott. (2003). Industrial Agglomeration and Development: A Survey of Spatial Economic Issues in East Asia and a Statistical Analysis of Chinese Regions. Economic Geography 79 (3), pp. 295-319.

Flury, B. K., Riedwyl, H. (1986) "Standard distance in univariate and multivariate analysis". The American Statistician. 40 pp. 249-251.

Gardiner, B., Martin, R., \& Tyler, P. (2010). "Does spatial agglomeration increase national growth? Some evidence from Europe". Journal of EconomicGeography, 11(6), pp. 979-1006

Geppert, K., Marti, G \& Axel, W. (2008). "Economic Growth of Agglomerations and Geographic Concentration of Industries: Evidence for West Germany", Regional Studies, 42(3), pp. 413-421.

Glaeser, E., H. Kallal, J. Sheinkman, and A. Schleifer (1992), "Growth in Cities", Journal of Political Economy, 100, pp. 1126-1152. 
Journal of Applied Economics and Business Studies, Volume. 4, Issue 4 (2020) 187-214 https://doi.org/10.34260/jaebs.449

Heckman, J., Ichimura, H. \& Todd, P. (1997), "Matching as an Econometric Evaluation Estimator: Evidence from Evaluating a Job Training Program", Review of Economic Studies, 64(4), pp. 605-654.

Heckman, J., Ichimura, H., Smith, J. \& Todd, P. (1998), "Characterization of Selection Bias Using Experimental Data", Economelrica, 66(5), pp. 1017-98.

Heckman, J., Robert, L \& Smith, J. (1999)."The economics and econometrics of active labor market programs". In Handbook of labor economics, 3(1), pp. 1865-209.

Henderson, V., A. Kuncoro, and M. Turner (1995), "Industrial Development in Cities", Journal of Political Economy, 103, pp.1067-1152.

Imbens, G. (2004): "Nonparametric Estimation of Average Treatment Effects under Exogeneity: A Review," The Review of Economics and Statistics, 86(1), pp. 4-29.

Jamal, H (2006). "Does inequality matter for poverty reduction? Evidence from Pakistan's poverty trends" The Pakistan Development Review 45(3), pp. 439-459

Khan, S., and E. Tamer (2010), "Irregular Identification, Support Conditions and Inverse Weight Estimation," Econometrica, 78 (6), pp. 2021-2042.

Kim, S. (2008) "Spatial Inequality and Economic Development: Theories, Facts, and Policies". Commission on Growth and Development, working paper No.16

Krugman, P. (1991) "Geography and Trade" Cambridge: M.I.T. Press,

Marshall, A. (1890) "Principles of Economics" London.

Maurel, F., B. Sedillot (1999) "A Measure of the Geographic Concentration in French Manufacturing Industries", Regional Science and Urban Economics, 29, pp. 575604.

Midelfart, K. H. (2004) "Does agglomeration explain regional income inequalities?" Norwegian School of Economics and Business Administration and CEPR

Naseer, S. \& Ahmed, A. M. (2016) "Determinants of Income Inequality among the Earners in Pakistan" $\mathrm{S}^{3} \mathrm{H}$ Working Paper Series, National University of Sciences and Technology (NUST).

Normand S.L. T., Landrum M.B., Guadagnoli E., Ayanian J.Z., Ryan T.J., Cleary P.D., McNeil B.J.(2001) "Validating recommendations for coronary angiography following an acute myocardial infarction in the elderly: A matched analysis using propensity scores". Journal of Clinical Epidemiology. pp. 387-398.

Rosenbaum, P. R., \&. Rubin, D. B. (1983a) "The central role of the propensity scores in observational studies for causal effects." Biometrika., 70, pp. 41-55

Rosenbaum, P. R., \&. Rubin, D. B. (1983b). "Assessing sensitivity to an unobserved binary covariate in an observational study with binary outcome." Journal of the Royal Statistical Society, Series B. 45, pp.212-218.

Rosenbaum, P. R., \&. Rubin, D. B. (1985) "Constructing a control group using multivariate matched sampling methods that incorporate the propensity score." The American Statistician 39(1), pp. 33-38

Sial, M.S., Zheng, C., Khuong, N.V., Khan, T., Usman, M. (2018), "Does firm performance influence corporate social responsibility reporting of chinese listed companies?" Sustainability, 10(7), pp. 1-12.

Tabassum, U. (2016)"Regional Specialization Trade and economic size of cities" Thesis " University of Karachi. 
Uzma Tabassum, Shaista Alam and Ambreen Fatima

Weber A, (1909) Über den Standort der Industrien (Mohr, Tübingen). Translated by C. J. Friedrich, 1929, as Alfred Weber's Theory of the Location of Industries (University of Chicago Press, Chicago) 
Table A1: Estimates of Probit Model (If Agglomeration=1)

\begin{tabular}{|c|c|}
\hline Variables & Coefficient \\
\hline Average schooling & $\begin{array}{l}0.075 * * * \\
(0.00517)\end{array}$ \\
\hline Age of highest earner & $\begin{array}{l}0.009 * * * \\
(0.00092)\end{array}$ \\
\hline Education of highest earner & $\begin{array}{l}-0.012 * * * \\
(0.0044)\end{array}$ \\
\hline Age of head of household & $\begin{array}{l}0.005 * * * \\
(0.00093)\end{array}$ \\
\hline Dependency Ratio & $\begin{array}{l}0.0184 * * \\
(0.00802)\end{array}$ \\
\hline Migrant household & $\begin{array}{l}0.394 * * * \\
(0.0440)\end{array}$ \\
\hline Technical/Vocational training & $\begin{array}{c}0.266 * * * \\
(0.0410)\end{array}$ \\
\hline Working age members in household & $\begin{array}{l}0.0224 * * * \\
(0.00589)\end{array}$ \\
\hline Gender of $\mathrm{HOH}$ & $\begin{array}{c}0.298 * * * \\
(0.0445)\end{array}$ \\
\hline Work hours & $\begin{array}{l}0.0099 * * * \\
(0.00118)\end{array}$ \\
\hline Female Participation Rate & $\begin{array}{c}-0.282 * * * \\
(0.0351)\end{array}$ \\
\hline Constant & $\begin{array}{c}-1.617 * * * \\
(0.246)\end{array}$ \\
\hline Occupational dummies & \multirow[t]{2}{*}{$\begin{array}{l}\text { Most of the dummies appears } \\
\text { statistically significant }\end{array}$} \\
\hline Provincial dummies & \\
\hline Observations & 18,722 \\
\hline LR chi2(46) & $3143.96^{* * *}$ \\
\hline Pseudo R2 & 0.215 \\
\hline
\end{tabular}

Standard errors in parentheses

$* * * \mathrm{p}<0.01, * * \mathrm{p}<0.05, * \mathrm{p}<0.1$

Source: Author's estimations based on LFS 2017-18 
Table A-2: Distribution of Estimated Propensity Score-Livelihood

\begin{tabular}{|rrrrr}
\hline Percentiles & \multicolumn{2}{c}{ Smallest } & & \\
\hline $\mathbf{1 \%}$ & 0.007168 & 0.002032 & & \\
$\mathbf{5 \%}$ & 0.014106 & 0.0023592 & & 18722 \\
$\mathbf{1 0 \%}$ & 0.021964 & 0.0025063 & Obs & 18722 \\
$\mathbf{2 5 \%}$ & 0.106504 & 0.0025063 & Sum of Wgt. & 0.25002 \\
$\mathbf{5 0 \%}$ & 0.251298 & & Mean & 0.167869 \\
\hline & \multicolumn{2}{c}{ Largest } & Std. Dev. & \\
$\mathbf{7 5 \%}$ & 0.36499 & 0.8400924 & & 0.02818 \\
$\mathbf{9 0 \%}$ & 0.466755 & 0.8439572 & Variance & 0.349559 \\
$\mathbf{9 5 \%}$ & 0.536866 & 0.8474239 & Skewness & 2.591341 \\
$\mathbf{9 9 \%}$ & 0.678517 & 0.8526713 & Kurtosis & 0.349559 \\
$\mathbf{9 5 \%}$ & 0.536866 & 0.8474239 & Skewness & 2.591341 \\
\hline $\mathbf{9 9 \%}$ & 0.678517 & 0.8526713 & Kurtosis & \\
\hline
\end{tabular}

Note: The region of common support is [.002032, .8526713]

Source: Author's estimations based on LFS 2017-18 